\title{
Antibacterial Properties of Biofilm Schiff Base Derived from Dialdehyde Cellulose and Chitosan
}

\author{
Agung Pratama, Firman Sebayang ${ }^{*}$, and Rumondang Bulan Nasution \\ Department of Chemistry, Faculty of Mathematics and Natural Sciences, University of Sumatera Utara, \\ Jl. Bioteknologi No.1, Kampus USU, Medan 20155, Indonesia
}

${ }^{*}$ Corresponding author:

email: firman1@usu.ac.id

Received: April 13, 2018

Accepted: August 10, 2018

DOI: $10.22146 /$ ijc.34721

\begin{abstract}
Cellulose and chitosan are natural polymers that have been used as biocomposite. The aim of this research is to obtain biofilms from chitosan and oxidized cellulose crosslinks. This research is divided into three steps, i.e., isolation of cellulose from oil palm trunk and oxidation of cellulose using $\mathrm{NaIO}_{4}(0.2 ; 0.4 ; 0.6 ; 0.8 ; 1.0 \mathrm{mg} / \mathrm{mL})$ to obtain dialdehyde cellulose (DAC), crosslink of oxidized cellulose with chitosan (DD = 72.85\%) to obtain biofilm of chitosan/DAC (CDAC), and characterization of biofilms. The crosslinked reaction was confirmed by FT-IR analysis that showed the spectrum of Schiff base $C=N$ group at $1651 \mathrm{~cm}^{-1}$. Tensile strength increased gradually when the $\mathrm{NaIO}_{4}$ concentration used was $0.2-0.6 \mathrm{mg} / \mathrm{mL}$, but after those concentrations, the tensile strength slightly decreased. The morphology analysis showed that CDAC had smoother morphology than DAC, which was shown rough and showed some particle indicated the presence of unreacted cellulose. CDAC biofilms that prepared with $1.0 \mathrm{mg} / \mathrm{mL} \mathrm{NaIO}$ showed the greatest antibacterial activity.
\end{abstract}

Keywords: biofilm; cellulose; chitosan; dialdehyde cellulose, Schiff base

\section{- INTRODUCTION}

New packaging with bioactive potential has attracted significant interest in the food packaging industry since the last decade. It is caused by the ability to improve the shelf life, safety and sensory properties resulted in maintaining the quality of the food [1-2]. Packaging with antimicrobial properties is a promising packaging for improving the quality of the food also it has received attention as the new potential packaging that able to inhibit pathogenic microorganism in food [3-4].

Any method can be used to develop the antimicrobial packaging, i.e., by adding an antimicrobial agent into the polymer matrix. This method may give a significant result on shelf-life extension and food quality. But, most of the packaging material on the market nowadays is made from synthetic polymers that based on petrochemical. The packaging based on petrochemical is still a big issue today because their solid waste is unable or needs a long time to degrade. That issue attracted the researchers to find new material from a natural polymer that suitable for development as bio-packaging (biofilm).
Polysaccharide has attracted the world to their biological impact, such as antioxidant, antimicrobial, antiviral, antitumor and immunomodulatory activities. The other impact of this material is the usage in the treatment of hepatitis and cardiovascular [5-9]. Chitosan is one kind of polysaccharides that commonly used as bio-packaging; it derived from crustacean shell through demineralization and deacetylation process [1,10-11]. In nature, chitosan is the second abundant polysaccharide after cellulose material. As like cellulose, chitosan also has several properties that make it utilized in any sectors, such as excellent biocompatibility, biodegradable and antimicrobial activity [12]. Chitosan after deacetylation process consists of a free amino group; this amine group has a big role in the antimicrobial activity of chitosan $[1,11]$. Improvement in the antimicrobial activity of chitosan can be reached by structure modification or structure functionalization of chitosan. The free amino group in chitosan, make chitosan more applicable for further functionalization, the popular one is a Schiff base reaction [13]. Schiff base reaction is the reaction that 
occurred between the free amine group of chitosan with the carbonyl group of aldehyde or ketone [14]. The Schiff base functionalization could improve the antimicrobial activity of chitosan[15].

The Schiff base material can be a promising antimicrobial packaging that depends on the sources of the carbonyl group. Many kinds of Schiff base materials are readily available that based on natural polymer, making the Schiff base material to be an eco-friendly material. $\alpha$-Cellulose or cellulose can be used as the sources of carbonyl group through oxidation reaction using periodate acid or periodate salt. The present work is aimed to develop Schiff base antimicrobial film from commercial chitosan and cellulose dialdehyde (it obtained from periodate oxidation of oil palm's $\alpha$-cellulose or cellulose). The research focuses on the influence of the degree of oxidation (DO) of prepared dialdehyde cellulose on the antimicrobial activity of the obtained Schiff base film. The obtained film with a different degree of oxidation of the prepared cellulose dialdehyde was then tested for their mechanical testing and antimicrobial properties against Escherichia coli, Staphylococcus aureus, and Candida albicans.

\section{- EXPERIMENTAL SECTION}

\section{Materials}

Chitosan (DD $=72.85 \%$ ) was obtained from CV. Agung Menara Abadi while cellulose isolated from oil palm trunks. $\mathrm{NaOH}, \mathrm{HCl}, \mathrm{NaIO}_{4}$, acetate buffer, $\left(\mathrm{NH}_{4}\right)_{2} \mathrm{Fe}\left(\mathrm{SO}_{4}\right)_{2}$, $\mathrm{KMnO}_{4}, \mathrm{CH}_{3} \mathrm{COOH}$, and $\mathrm{NaCl}$ were obtained from Merck. The antibacterial test was conducted at the Laboratory of Microbiology, Department of Biology, USU.

\section{Instrumentation}

Fourier transforms infrared (FTIR) spectrum was recorded by Shimadzu IR-420. The surface morphology of the crosslinked CDAC was determined by EPOMH 10 ZSS EDX SEM. Tensile strength and elongation testing were performed by tensile test instrumentation GOTECH AL-7000M.

\section{Procedure}

\section{Isolation and oxidation of a-cellulose}

The powder of oil palm trunk (75 g) was treated with
$1 \mathrm{~L}$ of $3.5 \%$ nitric acid containing $10 \mathrm{mg}$ of sodium nitrite for $2 \mathrm{~h}$ and heated with stirring at $90{ }^{\circ} \mathrm{C}$, followed by filtering and washing until the neutral fiber was obtained. The neutral fiber was digested with $750 \mathrm{~mL}$ solution containing $2 \%(\mathrm{w} / \mathrm{v})$ each of sodium hydroxide and sodium sulfite at $50^{\circ} \mathrm{C}$ for $1 \mathrm{~h}$. Furthermore, the neutral fiber was bleached with $250 \mathrm{~mL}$ of sodium hypochlorite $1.75 \%$ at $70{ }^{\circ} \mathrm{C}$ for $0.5 \mathrm{~h}$. The washed and filtered material was next treated with $500 \mathrm{~mL}$ of $17.5 \%(\mathrm{w} / \mathrm{v})$ sodium hydroxide at $80^{\circ} \mathrm{C}$ for $0.5 \mathrm{~h}$. The resulting a-cellulose was washed thoroughly with water. The isolation process was then completed by whitening with a 1:1 aqueous dilution of hydrogen peroxide $10 \%$ at $60{ }^{\circ} \mathrm{C}$ and subsequent washing with water until the filtrate was clear. The cellulose material was then filtered, and water was manually squeezed out in the oven, which was dried at $60{ }^{\circ} \mathrm{C}[16]$.

$\alpha$-Cellulose were immersed in solutions of sodium periodate in $0.1 \mathrm{M}$ acetate buffer (liquor ratio $1: 100, \mathrm{w} / \mathrm{v}$ ) at various concentration of sodium periodate $0.2 ; 0.4$; $0.6 ; 0.8 ; 1.0 \mathrm{mg} / \mathrm{mL}$. The mixture was stirred mildly in the absence of light at $\mathrm{pH} 4.5$ and $40^{\circ} \mathrm{C}$ for $60 \mathrm{~min}$. After completion of oxidation, the cellulose was washed with distilled water several times to remove the oxidant at room temperature. This oxidized cellulose was used for the chitosan treatment without drying [17].

\section{Determination of the degree of oxidation (DO) of cellulose}

Oxidized cellulose was reacted with Fehling's solution for $2 \mathrm{~h}$ at $35^{\circ} \mathrm{C}$, then washed to remove the remnants of the reactants until the washing solution is colorless (solution A). The presence of the aldehyde group on oxidized cellulose was indicated by reddish color. The solution of $0.05 \mathrm{M}$ ferrous ammonium sulfate was added to the solution A and titrated with $0.02 \mathrm{M}$ of potassium permanganate solution. The necessary amount of the reacted potassium permanganate with ferrous sulfate will be proportional to the amount of $\mathrm{Cu}^{2+}$ that reduced by ferrous ammonium sulfate.

The reduced $\mathrm{Cu}^{2+}$ ion indicated the amount of the aldehyde group in the cellulose chain [18]. The copper number $(\mu \mathrm{mol} / \mathrm{g})$ can be calculated by using equation 1 .

\footnotetext{
Agung Pratama et al.
} 
Copper number $=\frac{(\mathrm{V} 1-\mathrm{V} 2) \times \mathrm{NKMnO}_{4}}{\mathrm{w} \times 1000} \times 100$

where V1: Volume of sample titrated; V2: Volume of the blank; and w: a mass of the sample.

The degree of oxidation of the cellulose is expressed as the number of carbonyl groups formed on dialdehyde cellulose compound. A linear relationship between the carbonyl content with a copper number $(\mu \mathrm{mol} / \mathrm{g})$ expressed by equation 2 [19].

Carbonyl content $=\frac{\text { Copper number }-0.07}{0.06}$

\section{Crosslink of chitosan onto oxidized cellulose}

A chitosan solution was prepared following this procedure: chitosan ( $8.0 \mathrm{~g}$ ) was placed in $400 \mathrm{~mL}$ of $2 \%$ $(\mathrm{v} / \mathrm{v})$ aqueous acetic acid solution, and the dispersion was stirred at $60{ }^{\circ} \mathrm{C}$ for $1 \mathrm{~h}$. Then, the oxidized cellulose was immersed in the chitosan solution with stirring for up to $2 \mathrm{~h}$ at $60{ }^{\circ} \mathrm{C}$ [17]. After that treatment, the obtained solution was poured over a petri dish and dried at $30{ }^{\circ} \mathrm{C}$ for one night. The formed film was characterized by FTIR, SEM, tensile strength/elongation, and the antibacterial activity was conducted as well.

\section{Characterization of chitosan-dialdehyde cellulose (CDAC) composite film}

FT-IR analysis. Approximately $1 \mathrm{mg}$ of dry CDAC composite film was pressed into a pellet with $200 \mathrm{mg}$ of potassium bromide, and Fourier Transform Infrared (FTIR) spectrum was recorded by Shimadzu IR-420 with an accumulation of 20 scans and a resolution of $4 \mathrm{~cm}^{-1}$.

SEM analysis. The surface morphology of the crosslinked product of CDAC was determined by EPOMH 10 ZSS EDX SEM with a magnification of $1500 \times$ and $2000 \times$. SEM analysis was conducted to study the morphology of those materials. From SEM analysis, we can see the result of mixing cavities between oxidized cellulose with chitosan. The information from this analysis will get the information the compatibility of each blends component.

Tensile strength and elongation test. Tensile strength and elongation testing were performed by a tensile test instrumentation GOTECH AL-7000M. Tensile test equipment must be conditioned on $2 \mathrm{kgf}$ load the pulling speed of $50 \mathrm{~mm} / \mathrm{min}$. The specimen is clamped strongly with a brace of tools. Then the machine is turned on, and the specimen to be drawn up and observed to drop.

The elongation at break (\%) of the material is calculated by equation 3 .

$\varepsilon=\frac{1-1_{0}}{l_{0}} \times 100 \%$

where, $1-l_{0}=$ value of stroke $(\mathrm{mm}) ; 1_{0}=$ initial length

While the tensile strength value $\left(\mathrm{kgf} / \mathrm{mm}^{2}\right)$ was calculated using equation 4 .

$\delta_{\tau}=\frac{F_{\text {maks }}(\mathrm{kgf})}{\mathrm{A}\left(\mathrm{mm}^{2}\right)}$

Antimicrobial activity. Antimicrobial activity of CDAC was performed on three types of microbes, i.e., $S$. aureus, E. coli, and C. albicans. The microbes culture were diluted in accordance with the standards McFarland, each inoculated into petri dishes containing Mueller Hinton agar. Then the disc was inserted into the blends of dialdehyde cellulose/chitosan in a petri dish aseptically. The petri dish then put in an incubator at $35{ }^{\circ} \mathrm{C}$ for $24 \mathrm{~h}$. After $24 \mathrm{~h}$, the antimicrobial zone (clear zone) was observed and measured in diameter by using a caliper.

\section{- RESULTS AND DISCUSSION}

\section{Extraction of a-Cellulose and Synthesis DAC}

Raw oil palm fiber was subjected to chemical treatment for removing hemicellulose and lignin so that the obtained $a$-cellulose will have micron size. Chemical treatments affected the color change of $\alpha$-cellulose powder (Fig. 1), which indicated that the chemical treatment successfully removed the hemicellulose and lignin which are the main components of the cell wall. The

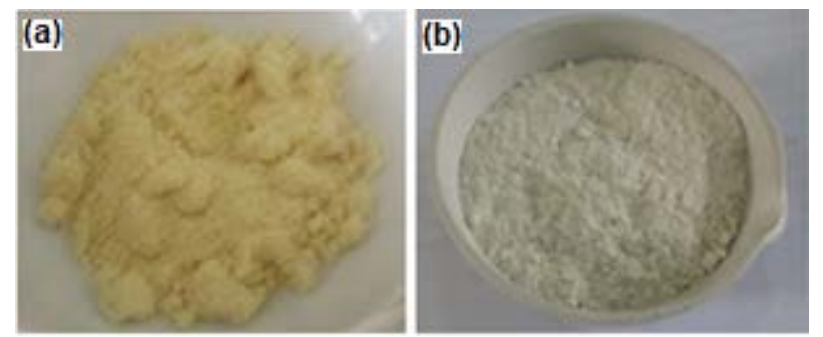

Fig 1. (a) Cellulose after the de-lignification process, (b) a-cellulose of the oil palm trunk 
removing process of hemicellulose and lignin from the raw material occurred during alkaline treatment by the hydrolysis process that leads to the formation of sugars and a phenolic compound. The removal of hemicellulose and lignin is the effect of the breakdown of the hydrogen bond at the C- 3 and C- 6 positions of the glucopyranose units. The hemicellulose and lignin are soluble in water, so it would completely remove from the fiber after the bleaching process using $\mathrm{H}_{2} \mathrm{O}_{2}$.

The oxidized cellulose was obtained from the oxidation reaction of $\alpha$-cellulose with periodate salt. This oxidation reaction can be identified as a specific reaction because the oxidation only occurred at the hydroxyl group of cellulose in the position C-2 and C-3 [20]. The transformation of a hydroxyl group into aldehyde was initiated by the breaking down the $\mathrm{C}-\mathrm{C}$ bond of the glucopyranose ring, leading to the formation of 2,3dialdehyde cellulose (DAC). The reaction of cellulose with $\mathrm{NaIO}_{4}$ can be seen in Fig. 2 .

\section{FTIR Analysis}

The changing in the functional group between $\alpha$ cellulose and DAC can be confirmed by the FTIR spectra analysis (Fig. 3). From the analysis of the functional group, $a$-cellulose of oil palm trunk showed a band at $3749 \mathrm{~cm}^{-1}$ which correspond to the hydrogen bond hydroxyl (-OH) group (not shown). The spectra also showed -OH group at $3448 \mathrm{~cm}^{-1}$ and a band of C-H stretching at $2893 \mathrm{~cm}^{-1}$. The signal at $1064 \mathrm{~cm}^{-1}$ indicated a $\mathrm{C}-\mathrm{O}$ bond from the hemiacetal ring of $\alpha$ cellulose.

The spectrum of DAC shows a well-defined characteristic peak at $1725 \mathrm{~cm}^{-1}(\mathrm{C}=\mathrm{O}$ stretching of the aldehyde groups) which is absent in the spectrum of $\alpha$ cellulose. This indicates DAC formation. In the previous study, the carbonyl group of two aldehyde groups appeared at $1726 \mathrm{~cm}^{-1}$ [21]. The difference result obtained in this work can be caused by the difference condition of reaction, as seen in the work of Rangel-Vazquez [20], the<smiles>COC1OC(CO)C(O)C(O)C1O</smiles>

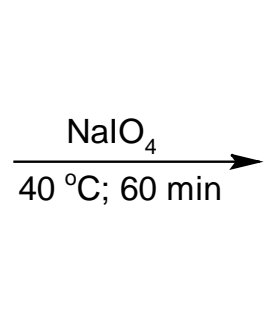<smiles>COC(C)C(C=O)O[C@@H](C=O)OC</smiles>

Dialdehyde Cellulose (DAC)

Fig 2. The reaction of cellulose with $\mathrm{NaIO}_{4}$

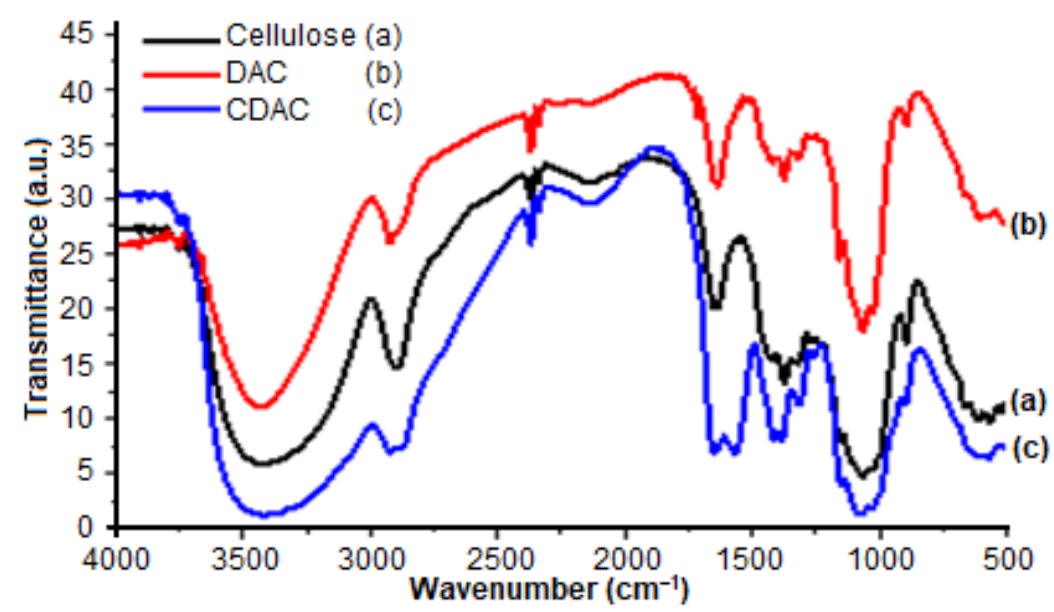

Fig.3. FT-IR spectra cellulose, DAC, and CDAC 
oxidation time has a big influence to the number of an aldehyde group, and it would influence the result in FTIR spectra.

The peak of carbonyl group completely disappears in nanocomposite (CDAC), and a new prominent peak can be observed at $1651 \mathrm{~cm}^{-1}(\mathrm{C}=\mathrm{N}$, characteristic of imine) [17]. Thus, the formation of a Schiff-base is supported by the FTIR data.

\section{SEM Analysis}

The SEM surface figures of CDAC and DAC can be seen in Fig. 4. The surface morphology of CDAC was shown smoother than DAC, which showed rough and had some particle indicated the presence of unreacted cellulose. According to Liu [17], DAC has rough surfaces as the impact of the oxidation reaction that changes the crystallinity of cellulose. The crystallinity of DAC was $42.73 \%$ while the addition of chitosan reduced the crystallinity to $39.15 \%$. The presence of chitosan during crosslinked reaction with DAC caused the surface of CDAC to become smoother. The chitosan acts as a coupling agent that serves to bind the fine threads into the DAC fiber and fill in the rough surface caused by the oxidation reaction. Therefore, it could improve the mechanical properties of the material.

\section{Influence of Oxidation Degree of DAC to the Properties of the Composite}

From Fig. 5, it can be seen that the concentration of $\mathrm{NaIO}_{4}$ had a linear relationship with the degree of oxidation of cellulose. The content of the aldehyde group increased from 0.40 to $5.73 \mu \mathrm{mol} / \mathrm{g}$ with increasing concentrations of $\mathrm{NaIO}_{4}$. This can be explained that the glucose monomers on the oxidized cellulose chain is sensitive and will undergo chain termination at the terminal monomer unit and the parts that are dissolved by periodate ions at higher concentrations diffuse to the surface and into the cellulose molecule.

Testing of tensile strength and elongation in this study used a load of $2 \mathrm{kgf}$ with a specimen length of $60 \mathrm{~mm}$, a width of $16 \mathrm{~mm}$ and a thickness of $0.1 \mathrm{~mm}$. The test results of tensile strength and elongation can be seen in Table 1.

An important factor that affects the mechanical properties of a film is the affinity between each of its constituent components. Affinity is a phenomenon in which atoms or certain molecules tend to unite or bind. With the increased affinity, the more the bond between molecules occurs.
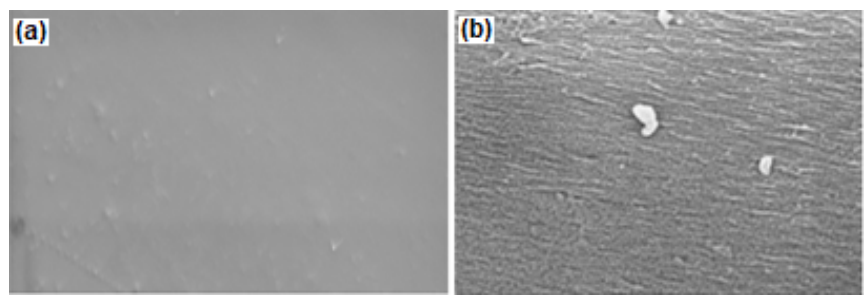

Fig 4. SEM Surface of (a) CDAC and (b) DAC

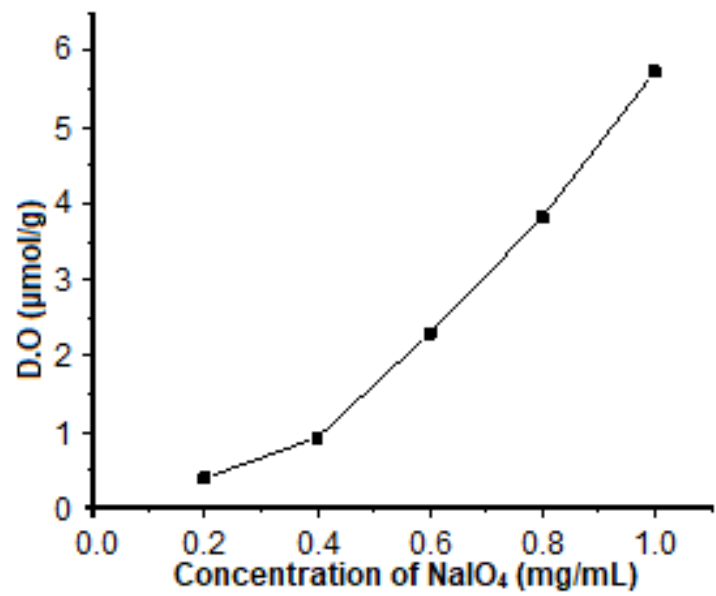

Fig 5. The relationship between the concentration of $\mathrm{NaIO}_{4}$ with D.O

Table 1. Data test result in tensile strength and elongation

\begin{tabular}{lcccc}
\hline \multirow{2}{*}{ No. } & \multicolumn{2}{c}{ Formulation } & $\begin{array}{c}\text { Tensile Strength } \\
\left(\mathrm{kgf} / \mathrm{mm}^{2}\right)\end{array}$ & $\begin{array}{c}\text { Elongation } \\
(\%)\end{array}$ \\
\cline { 2 - 3 } & Chitosan $(\% \mathrm{w} / \mathrm{v})$ & Cellulose $(\mathrm{g}): \mathrm{NaIO}_{4}(\mathrm{mg} / \mathrm{mL})$ & $3.94 \pm 0.014$ & $3.87 \pm 0.010$ \\
2 & 2 & $1.0: 0.2$ & $4.28 \pm 0.010$ & $3.19 \pm 0.020$ \\
3 & 2 & $1.0: 0.4$ & $7.18 \pm 0.011$ & $3.20 \pm 0.005$ \\
4 & 2 & $1.0: 0.6$ & $4.52 \pm 0.040$ & $2.80 \pm 0.231$ \\
5 & 2 & $1.0: 0.8$ & $4.40 \pm 0.400$ & $4.69 \pm 0.040$ \\
\hline
\end{tabular}


Table 2. Data of the inhibition zone

\begin{tabular}{lccccc}
\hline \multirow{2}{*}{ No. } & Sample of & \begin{tabular}{c} 
Concentration of $\mathrm{NaIO}_{4}$ \\
\cline { 3 - 5 }
\end{tabular} & Material & $(\mathrm{mg} / \mathrm{mL})$ & \multicolumn{3}{c}{ Zone of Inhibition $(\mathrm{mm})$} \\
\hline 1 & CDAC- 1 & 0.2 & - & - & - \\
2 & CDAC-2 & 0.4 & - & - & - \\
3 & CDAC-3 & 0.6 & - & - & - \\
4 & CDAC-4 & 0.8 & 8.05 & 11.05 & - \\
5 & CDAC-5 & 1.0 & 10.60 & 13.45 & - \\
\hline
\end{tabular}
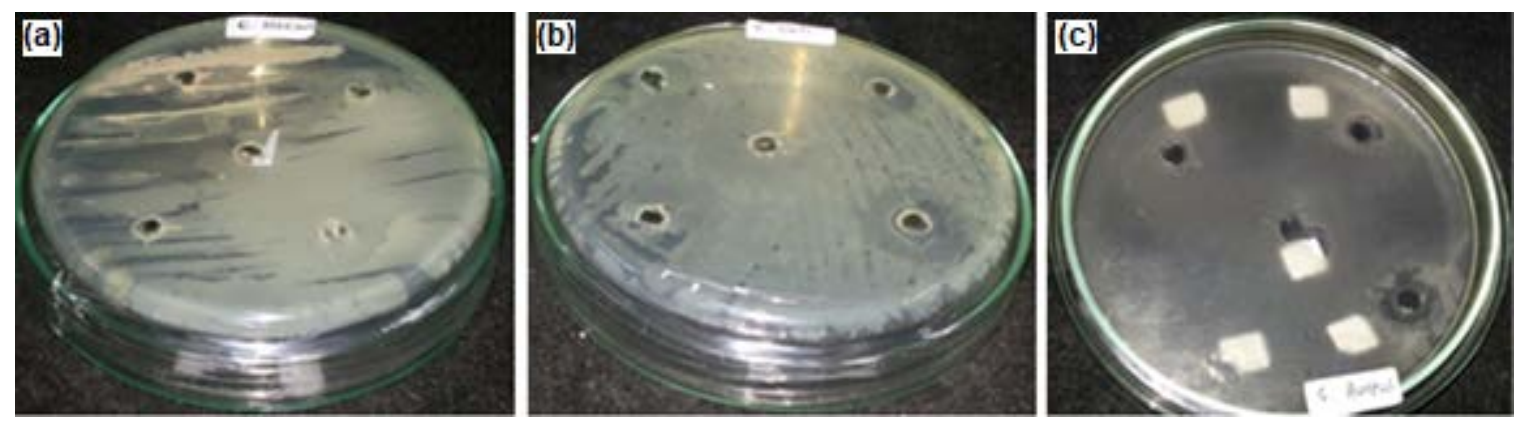

Fig 6. Results of the antimicrobial testing of (a) C. albicans, (b) E. coli, and (c) S. aureus

From Table 1, it can be seen that the tensile strength of the film increased as the increase of the concentration of $\mathrm{NaIO}_{4}$ from 0.2 to $0.6 \mathrm{mg} / \mathrm{mL}$. However, when the concentration of $\mathrm{NaIO}_{4} 0.8$ to $1.0 \mathrm{mg} / \mathrm{mL}$, its strength decreased. The higher the concentration of $\mathrm{NaIO}_{4}$ the more cellulose is oxidized thereby increasing the affinity of the molecule of chitosan to cellulose molecules oxidized. When affinity between the molecules making up the material increases, the more the molecules of chitosan have reacted to the oxidized cellulose molecules through Schiff base reaction.

But when the oxidant concentration was $0.6 \mathrm{mg} / \mathrm{mL}$, the affinity between the molecules of chitosan and oxidized cellulose molecules reaching the maximum and begins to decrease its power when the oxidant concentration was $0.8 \mathrm{mg} / \mathrm{mL}$. This is because the molecular equilibrium has elapsed so that the affinity between components decreased.

The antimicrobial activity conducted on three types of microbes, i.e., E. coli representing the Gram-negative bacteria $S$. aureus which represents Gram-positive bacteria, and C. albicans that represent fungi. Results of the antimicrobial activity after $24 \mathrm{~h}$ can be seen in Fig. 6 , whereas inhibition zone measurement results of each microbe presented in Table 2.
From Table 2, it can be seen that only CDAC- 4 and CDAC-5 were able to inhibit the bacterial activity. This shows that the higher the concentration of oxidizing the more the chitosan molecules that combine to form a Schiff base compound, the greater their potential to inhibit the bacteria. The presence of chitosan in the film of CDAC had a big influence on the antibacterial activity of CDAC because the neat DAC film has no antibacterial activity [22].

Both of CDAC materials that inhibit bacterial growth indicated that the CDAC has a greater bactericidal against Gram-positive bacteria S. aureus than Gramnegative bacteria $E$. coli. It is caused by the differences in the building blocks of the cell wall structure of Grampositive and Gram-negative. The lipid content in the cell wall of Gram-positive is around 1-4\%, while in Gramnegative bacteria is around $11-22 \%$. The higher lipids contained in the cell walls of bacteria, the hydrolysis effect will be stronger, this will influence the performance of chitosan as an antimicrobial polycationic become more dominant in inhibiting the growth of bacteria. In addition, the cell wall of Grampositive bacteria only a single layered, whereas the Gram-negative bacteria have three layers [23]. Both of these factors lead to Gram-positive bacteria are more 
susceptible to the inclusion of antimicrobial compounds through the cell wall compared to Gram-negative bacteria.

\section{- CONCLUSION}

Biofilm of CDAC-4 and CDAC- 5 based on chitosan-dialdehyde cellulose (CDAC) could act as an effective antibacterial. Both of biofilm showed greater antibacterial properties against Gram-positive bacteria compared to the Gram-negative bacteria. Tensile strength increased gradually when the $\mathrm{NaIO}_{4}$ concentration is $0.2-$ $0.6 \mathrm{mg} / \mathrm{mL}$, but after those concentrations, the tensile strength slightly decreased. The morphology analysis of CDAC showed a smoother morphology than DAC, which showed rough and having some particle indicated the presence of unreacted cellulose.

\section{- REFERENCES}

[1] Ren, L., Yan, X., Zhou, J., Tong, J., and Su, X. , 2017, Influence of chitosan concentration on mechanical and barrier properties of cornstarch/chitosan films, Int. J. Biol. Macromol., 105 (Pt 3), 1636-1643.

[2] Mahieu, A., Terrié, C., and Youssef, B., 2015, Thermoplastic starch films and thermoplastic starch/polycaprolactone blends with oxygenscavenging properties: influence of water content, Ind. Crops Prod., 72, 192-199.

[3] Aider, M., 2010, Chitosan application for active biobased films production and potential in the food industry: Review, LWT Food Sci. Technol., 43 (6), 837-842.

[4] Dutta, P.K., Tripathi, S., Mehrotra, G.K., and Dutta, J., 2009, Perspectives for chitosan-based antimicrobial films in food applications, Food Chem., 114 (4), 1173-1182.

[5] Yang, W., Wang, Y., Li, X., and Yu, P., 2015, Purification and structural characterization of Chinese yam polysaccharide and its activities, Carbohydr. Polym., 117, 1021-1027.

[6] Tahmouzi, S., and Ghodsi, M., 2014, Optimum extraction of polysaccharides from motherwort leaf and its antioxidant and antimicrobial activities, Carbohydr. Polym., 112, 396-403.
[7] Sinha, S., Astani, A., Ghosh, T., Schnitzler, P., and Ray, B., 2010, Polysaccharides from Sargassum tenerrimum: Structural features, chemical modification, and anti-viral activity, Phytochemistry, 71 (2-3), 235-242.

[8] Ferreira, I.C.F.R., Heleno, S.A., Reis, F.S., Stojkovic, D., Queiroz, M.J.R.P., Vasconcelos, M.H., and Sokovic, M., 2015, Chemical features of Ganoderma polysaccharides with antioxidant, antitumor and antimicrobial activities, Phytochemistry, 114, 38-55.

[9] Liu, J.Y., Feng, C.P., Li, X., Chang, M.C., Meng, J.L., and $\mathrm{Xu}, \mathrm{L} . J ., 2016$, The Immunomodulatory and antioxidative activity of Cordyceps militaris polysaccharides in mice, Int. J. Biol. Macromol., 86, 594-598.

[10] Bansal, M., Chauhan, G.S., Kaushik, A., and Sharma, A., 2016, Extraction and functionalization of bagasse cellulose nanofibres to Schiff-base based antimicrobial membranes, Int. J. Biol. Macromol., 91, 887-894.

[11] Jayakumar, R., Prabaharan, M., Nair, S.V., and Tamura, H., 2010, Novel chitin and chitosan nanofibres in biomedical applications, Biotechnol. Adv., 28 (1), 142-150.

[12] Nikolajski, M., Wotschadlo, J., Clement, J.H., and Heinze, T., 2012, Amino-functionalized cellulose nanoparticles: preparation, characterization, and interactions with living cells, Macromol. Biosci., 12 (7), 920-925.

[13] Zhang, L., Zhang, Q., Zheng, Y., He, Z., Guan, P., He, X., Hui, L., and Dai, Y., 2018, Study of Schiff base formation between dialdehyde cellulose and proteins, and its application for the deproteinization of crude polysaccharide extracts, Ind. Crops Prod., 112, 532-540.

[14] Shi, L., Ge, H.M., Tan, S.H., Li, H.Q., Song, Y.C., Zhu, H.L., and Tan, R.X., 2007, Synthesis and antimicrobial activities of Schiff bases derived from 5-chloro-salicylaldehyde, Eur. J. Med. Chem., 42 (4), 558-564.

[15] Strnad, S., Sauperl, O., and Fras-Zemljic, L., 2010, "Cellulose Fibres Functionalised by Chitosan: 
Characterization and Application" in Biopolymers, Eds., Elnashar, M., IntechOpen, 181-200.

[16] Ohwoavworhua, F.O., and Adelakun, T.A, 2005, Phosphoric acid-mediated depolymerization and decrystallization of a-cellulose obtained from corn cob: Preparation of low crystallinity cellulose and some physicochemical properties, Trop. J. Pharm. Res., 4 (2), 509-516.

[17] Liu, X., and Xu, Y., 2014, Preparation process and antimicrobial properties of cross-linking chitosan onto periodate-oxidized bamboo pulp fabric, Fibers Polym., 15 (9), 1887-1894.

[18] Noerati , 2008, Sintesis Kitosan Karboksilat Sebagai Zat Anti Bakteri dan Anti Kusut pada Material Selulosa, Dissertation, Department of Chemistry, ITB, Bandung.

[19] Janjić, S., Kostić, M., Škundrić, P., Lazić, B., and Praskalo, J., 2013, Antibacterial fibers based on cellulose and chitosan, Contemp. Mater., 2 (3), 207218.
[20] Rangel-Vázquez, N.-A., Guilbert-Garcia, E., Salgado-Delgado, R., Rubio-Rosas, E., Hernandez, E.G., Vargas-Galarza, Z., and Crispin-Espino, I., 2010, Synthesis, and characterization of chitosancoated dialdehyde cellulose with potential antimicrobial behavior, J. Mater. Sci. Eng., 4 (12), 62-67.

[21] Strnad, S., Sauper, O., and Jazbec, A., and StanaKleinschek, K., 2008, Influence of chemical modification on sorption and mechanical properties of cotton fibers treated with chitosan, Text. Res. J., 78 (5), 390-398.

[22] Hou, Q., Liu, W., Liu, Z., Duan, B., and Bai, L., 2008, Characteristics of antimicrobial fibers prepared with wood periodate oxycellulose, Carbohydr. Polym., 74 (2), 235-240.

[23] Pelczar, M.J., 1972, Food Microbiology, $5^{\text {th }}$ ed., McGraw Hill Book Co. Inc., New York, 783. 